\title{
Synthesis of ozone from air via a polymer-electrolyte-membrane cell with a doped tin oxide anode.
}

\author{
Yun-Hai Wang, ${ }^{a}$ Shaoan Cheng, ${ }^{a}$ and Kwong-Yu Chan ${ }^{* a}$ \\ Receipt/Acceptance Data [DO NOT ALTER/DELETE THIS TEXT] \\ ${ }_{5}$ Publication data [DO NOT ALTER/DELETE THIS TEXT] \\ DOI: 10.1039/b000000x [DO NOT ALTER/DELETE THIS TEXT]
}

The generation of ozone from air using an electrochemical cell consisting of an air cathode, a polymer-electrolyte-membrane (PEM), and a doped tin oxide anode is reported. This synthesis is green compared to the conventional high-voltage corona discharge process since $\mathrm{NO}_{\mathrm{x}}$ formation is 10 eliminated; a higher ozone concentration is generated; and lower energy may be required.

\section{Introduction}

Ozone is a powerful oxidant in advanced oxidation processes for treating water and solids. Ozone is a green oxidant since it self decomposes in time, leaving no residual 15 effects. It can also oxidize persistant pathologens and contaminants more effectively than chlorine [1,2]. The conventional route to synthesize ozone is through high voltage corona discharge (CD) in air producing a 2 to $3 \%$ concentration of ozone [3]. The overall energy consumption 20 of the CD process is high since cooling and drying of air are needed in additional to the electrical energy. This process can produce $\mathrm{NO}_{\mathrm{x}}$ as a by-product unless pure oxygen is supplied, which will require additional energy. The energy required to purify air to oxygen is at least two times that of making ozone 25 from oxygen [4].

The alternative route of ozone generation via water electrolysis is attractive since no $\mathrm{NO}_{\mathrm{x}}$ could be generated and only a low voltage source is needed. If dissolved ozone is the 30 desired product, then the water electrolysis route is more direct and effective. Some losses of ozone to oxygen are expected in the slow dissolution of gaseous ozone generated by the $C D$ process due to self-decomposition. The electrochemical synthesis of ozone has been examined with a 35 number of anode materials [5-11]. The electrolytic route to generate ozone has been reviewed recently $[12,13]$. Until now, only low efficiency has been demonstrated and the most efficient anode material, lead dioxide is environmentally prohibitive for a general usage. A high current efficiency and 40 a high concentration of ozone have only been demonstrated recently by the authors using doped tin oxide electrode [14, 15]. Some previous reported investigations of water treatment used anodes with undoped tin oxide anodes [16] or tin oxide doped with different elements [17, 18]. The focus of these 45 investigations were direct electro-oxidation and little ozone was detected. Our previous results of high ozone generation $[14,15]$ were obtained in a three-electrode test cell containing different acid electrolytes. For corrosion and safety consideration, it will be desirable to have an acid free process, 50 particularly for domestic household applications. Furthermore, hydrogen generated at the cathode during electrolysis creates a safety concern. The water consumed during electrolysis will need to be replenished regularly to maintain the electrolyte for

\footnotetext{
${ }^{a}$ Department of Chemistry, The University of Hong Kong Pokfulam Road, Hong Kong.

*Fax:(852) 2857 1586l; E-mail: hrsccky@hku.hk

†Electronic Supplementary Information (ESI) available: [details of any supplementary information available should be included here]. See http://dx.doi.org/10.1039/b000000x/
}

sustained operation. We present here for the first time the use 55 of the highly efficient nickel-antimony doped tin oxide as the anode in a water filled polymer electrolyte membrane (PEM) cell fitted with an air cathode. Oxygen from air is consumed in the porous cathode and ozone is produced in pure water and can subsequently evolve into the gas phase for gaseous ozone 60 production. A $15 \%$ ozone concentration in the gas phase, 20 $\mathrm{mg} / \mathrm{L}$ dissolved ozone, and a $15 \%$ percent current efficiency are observed here. These ozone concentrations reported are much higher than the $\mathrm{CD}$ process. In the following sections, we describe the experimental setup, the mechanism of the ${ }_{65}$ electrode processes, and the broader implications of the results for general environmental applications.

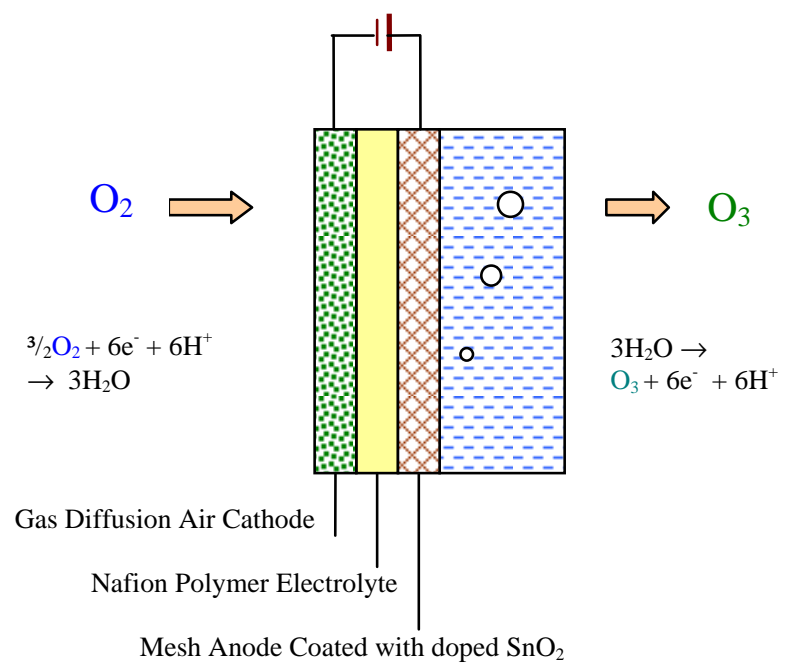

Fig. 1 Illustration of ozone generation in the electrochemical cell.

\section{Experimental}

\section{${ }_{70}$ The electrochemical cell}

The operation of the electrochemical generator is shown schematically in Fig. 1. Oxygen from air diffuses into the gas diffusion cathode and combines with protons to form water 75 when receiving electrons from the external circuit. Ozone is generated at the anode by oxidation of water with electrons released to the external ciruit, whereas protons are simultaneously produced. The protons subsequently diffuse through the proton exchange membrane back to the cathode. 80 The net reaction is converting oxygen to ozone without any consumption of water or protons. With the solid polymer electrolyte providing the protons, the ozone generation occurs 
in pure water without the need of an acid supporting electrolyte, and eliminate the corrosive hazard. The anode was ${ }_{85}$ prepared by repeated coating of a titanium mesh with an alcohol solution containing $\mathrm{SbCl}_{3}(\mathrm{BDH}, 99.5 \%), \mathrm{SnCl}_{4} \cdot$ $5 \mathrm{H}_{2} \mathrm{O}\left(98 \%\right.$, ABCR) and $\mathrm{NiCl}_{2} \cdot 6 \mathrm{H}_{2} \mathrm{O}$ (Merck, 98\%) precursors followed by pyrolysis at $500^{\circ} \mathrm{C}$. The procedure was similar to that previously described $[14,15]$. A $4.0 \mathrm{~cm}$ x 6.0 $90 \mathrm{~cm}$ titanium mesh (99.5\% Good Fellow) with a nominal aperture of $0.19 \mathrm{~mm}$ and wire diameter of $0.23 \mathrm{~mm}$ was spotwelded with a $1 \mathrm{~mm}$ diameter titanium wire $(99.5 \%$ Good Fellow). The mesh and wire assembly was then treated in $10 \%$ boiling oxalic acid for 1 hour, washed with distilled water, 95 and dried before dip-coated with the precursor solution and pyrolyzed in air. The dip coating and pyrolysis procedure was repeated 7 times and the loading on the Ti mesh was $61 \mathrm{mg}$ as determined by the weight gained. The cathode was prepared by pasting $55 \% \mathrm{Pt} / \mathrm{C}$ catalyst (De Nora North America, ETEK 100 Division) onto one side of a $4 \mathrm{~cm}$ x $6 \mathrm{~cm}$ carbon cloth (ETEK. $30 \%$ wet proofed). The platinum loading on the cathode was $4.5 \mathrm{mg} / \mathrm{cm}^{2}$. The membrane-electrolyte-assembly (MEA) was prepared by hot pressing at $140{ }^{\circ} \mathrm{C}$ the cathode, a solid electrolyte Nafion 117 membrane (Fuel Cell Scientific) and 105 the anode.

\section{Quantification of ozone production}

The amount of ozone generated was determined by a setup 110 as shown in Fig. 2. The water side of the MEA was housed in an acrylic chamber with an gas outlet connected to a $10 \%$ potassium iodide bath for idometric measurement. The ozone oxidized iodide to iodine stoichiometrically and the amount of iodine can be determined by titration with sodium thiosulfate 115 with a starch end point, as described in the literature [19]. The volume of the water chamber is $10 \mathrm{ml}$. After about $20 \mathrm{~min}$. of electrolysis, the ozone concentration in gas and water phase would have reached equilibrium. The generated gas was then let out through the tube and absorbed by the KI solution. The 120 unabsorbed residual gas was collected at the top of an inverted graduated cylinder to determine its volume, which was about $7 \mathrm{ml}$ after $30 \mathrm{~min}$. This unabsorbed gas is mainly oxygen generated from the reaction of ozone with KI, or from the electrolysis of water in the PEM. The ozone concentration in 125 the water phase was determined by UV spectrometer (Perkin Elmer Lambda 20). Water samples were extracted with a syringe from an opening fitted with a rubber septum. The ozone concentration in the gas phase can be calculated by the amount of ozone absorbed by the KI solution and the residual 130 gas volume at the top of the inverted cylinder.

The electrolysis was performed at constant cell voltage and controlled by a Radiometer Copenhagen/Dynamic-Eis Voltalab PGZ301 potentiostat/galvanostat. The number of 135 coloumbs passed during the electrolysis was accurately counted by a built-in integrator. All experiments were carried at room temperature of $20^{\circ} \mathrm{C}$.

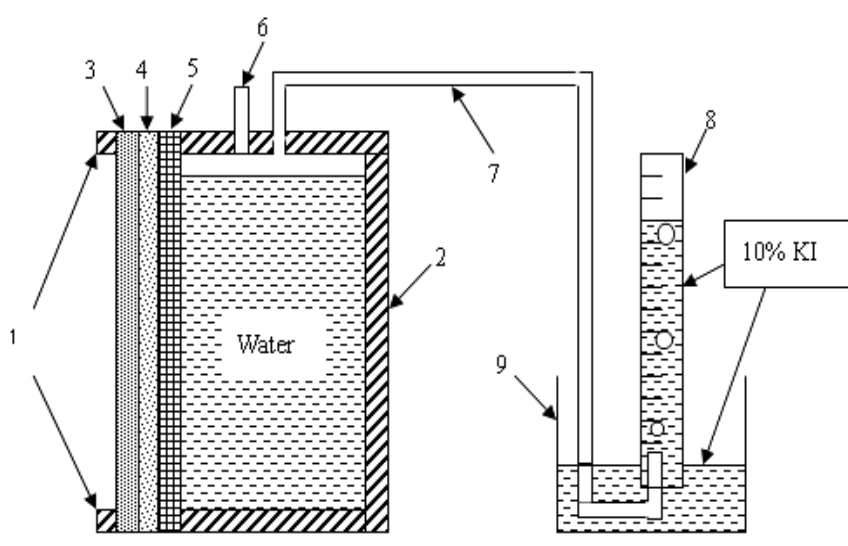

Fig. 2 The schematic drawing of the experimental apparatus. 1. Acrylic frame; 2 . Acrylic chamber; 3. Cathode; 4. Nafion membrane; 5 . Anode; 6. Hole for extracting water sample; 7 . Tube for gas transfer; $8.10 \mathrm{ml}$ cylinder with scale bar; 9 . Beaker.

\section{${ }^{140}$ Results and Discussion}

\section{Ozone concentration}

Using our experimental setup, we examine the issues of ozone synthesis in terms of ozone concentrations, current efficiency, 145 and energy efficiency. Upon application of a constant voltage across the PEM cell, ozone will be generated in water and accumulate until part of the ozone leaves the water phase to the gas phase above. As shown in the aqueous ozone concentration time profiles in Fig. 3, a steady-state is reached 150 after 25 minutes of applied voltage. At this point, ozone is generated steadily in water, enters into the gas phase, and is eventually absorbed by the KI solution in the absorption chamber. The steady-state dissovled ozone concentration depends on the applied voltage and varies in the range of 5 $155 \mathrm{mg} / \mathrm{L}$ to $20 \mathrm{mg} / \mathrm{L}$. This level of dissolved ozone cocentration is more than sufficient for most applications and is usually not attained in the conventional CD process [20]. Solubitiy of ozone in water depends on the gas phase ozone concentration, temperature, $\mathrm{pH}$, and the presence of other dissolved species. ${ }_{160}$ For a $48.5 \mathrm{mg} / \mathrm{L}$ ozone concentration $(\sim 2 \%)$ generated in the gas phase, the dissolved ozone concentration is $6.7 \mathrm{mg} / \mathrm{L}$ in a $\mathrm{pH} 7.1$ solution at $25{ }^{\circ} \mathrm{C}$ [21].

To avoid disturbance to the titration experiment and the 165 determination of steady-state gas phase ozone concentration, liquid samples were not withdrawn for dissolved ozone measurements after the 30th minute. The steady-state concentration of ozone in the gas phase correlates to that in the water phase and varies with applied voltage in the same 170 way, as shown in Fig. 4. The highest ozone concentration in gas phase was $15.6 \%(\mathrm{v} / \mathrm{v})$ equivalent to $334.3 \mathrm{mg} / \mathrm{L}$ (STP), at the voltage of $2.0 \mathrm{~V}$. This concentration is much higher than that achieved by the CD process, which is about $10 \%(\mathrm{v} / \mathrm{v})$ using a cool, dry, and pure oxygen supply [22]. 


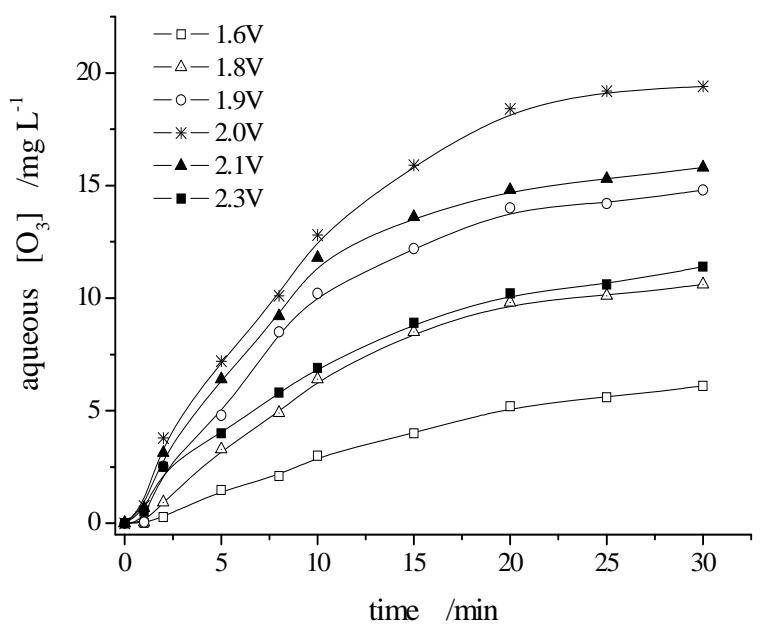

Fig. 3 Ozone concentration in water vs the electrolysis time at different voltage.

195 For applications requiring a source of high concentration gaseous ozone [22], the electrochemical process described here provides a convincing and convenient alternative to the CD process. Pure oxygen tank, cooling, and drying are not required in the electrochemical cell. The scalable and 200 modularizable generation is particularly attractive for small and medium scale usage. Previously, a complex procedure was adopted to provide high concentration gaseous ozone to some processes of preparing semi-conductor surfaces [23].

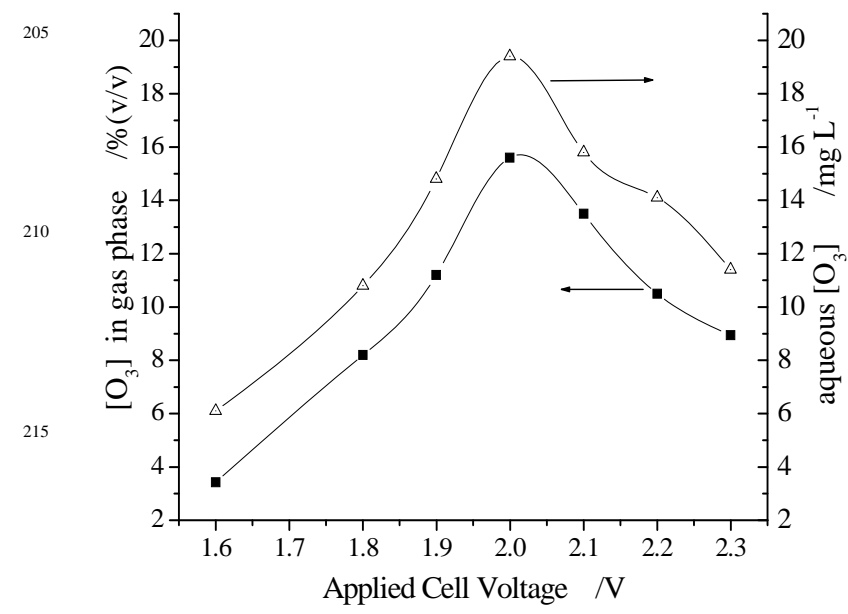

220

Figure 4. Applied voltage vs ozone concentration in gas and water phases.

\section{${ }_{225}$ Current efficiency}

Figures 3 and 4 show an optimum cell voltage of $2.0 \mathrm{~V}$ for highest ozone concentration. The effect of the cell voltage can be partly analysed in light of the parallel electrochemical oxidation of water to form oxygen,

230

$$
2 \mathrm{H}_{2} \mathrm{O} \longrightarrow 4 \mathrm{H}^{+}+4 \mathrm{e}^{-}+\mathrm{O}_{2},
$$

which has an equilibrium potential of $1.23 \mathrm{~V}$ (RHE). The oxygen evolutaion reaction is thermodynamically more 235 favorable than the ozone reaction

$$
3 \mathrm{H}_{2} \mathrm{O} \longrightarrow 6 \mathrm{H}^{+}+6 \mathrm{e}^{-}+\mathrm{O}_{3},
$$

which has an equilibrium potential of $1.52 \mathrm{~V}$ (RHE).

240 The presumed role of the doped tin oxide material at the anode is to suppress the kinetics of oxygen evolution reaction and enhance the activation of the ozone generation reaction. Equations (1) and (2) represent only the overall reactions and the detailed mechanisms may involved individual steps of 245 precursors and intermediates such as oxygen and hydroxyl free radicals, adsorbed oxygen, and other ions. The specific effect of voltage and materials to individual steps would require more refined experimental works. The electrochemical kinetics of the oxygen evolution reaction and the ozone 250 generation reaction are different. The increase of voltage beyond a certain value may promote more oxygen generation than ozone generation. The decrease of ozone concentration beyond the optimum voltage of $2.0 \mathrm{~V}$ can be partly explained by this reasoning. It is also possible that the catalytic material 255 or other electrode components are degraded by a high voltage.

While the efficiency of ozone generation falls over beyond 2.0 $\mathrm{V}$, the current increases steadily and linearly with applied voltage, as shown in Fig. 5. The effectiveness of using 260 current to produce ozone can be quantified by the current efficiency which is defined according to Faraday's law as

$$
\eta=[(\text { moles of ozone generated }) \mathrm{n} * \mathrm{~F} / \mathrm{C}] \times 100 \%,
$$

265 where $n$ is the number of electrons transferred $(n=6$ in equation 2), $\mathrm{F}$ is the Faraday's constant, and $\mathrm{C}$ is the amount of electric charge passed.

The $15.2 \%$ current efficiency observed at $2.0 \mathrm{~V}$ is the highest 270 value reported for a MEA cell with a static water electrolyte, whereas a value of $<10 \%$ was reported for $\mathrm{PbO}_{2}$ anode without water flow at room temperature [24-27].

The loss of current efficiency is mainly due to production of 275 oxygen either directly as the parallel electrochemical step of equation (1) or the subsequent decompostion of ozone to oxygen in the water phase and in the gas phase. The half-life of ozone at room temperature is 30 minutes and some losses of ozone to oxygen are expected. It has been demonstrated 280 [26] that current efficiency will improve by as much as $50 \%$ with forced convection of water. We may therefore expect the current efficiency reaching over $20 \%$ in our MEA cell with flowing water.

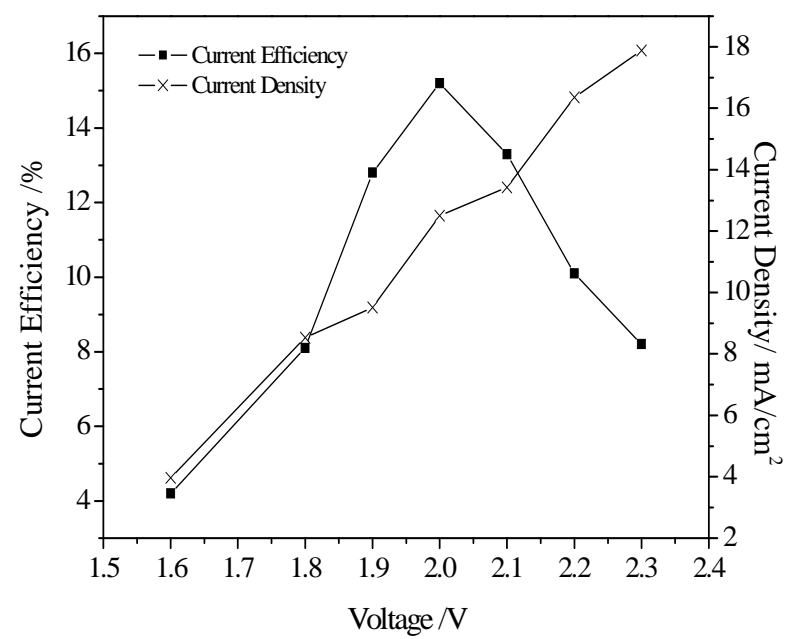

[JOURNAL], 200X, 00, 0000 $\mid 3$ 
A further increase in current efficiency can be envisaged by 290 improving the interfacial contact of the anode and the solid polymer electrolyte. A 36.2\% current efficiency was observed in our previous work using a wet acidic electrolyte [15] where the immersed mesh electrode was in more complete contact with protons and water. In the MEA construction, the mesh 295 anode and the solid electrolyte has a planer interfacial contact and the solid-solid interface has limited contact area. Onda et al. [26] has shown that by using a multi-layer mesh structure in contact with Nafion, interfacial contact can be improved and the ozone concentration can be increased by $40 \%$ 300 compared to a single layer mesh electrode. We may expect a further improvement with a better interfacial contruction between the anode and the solid polymer electrolyte.

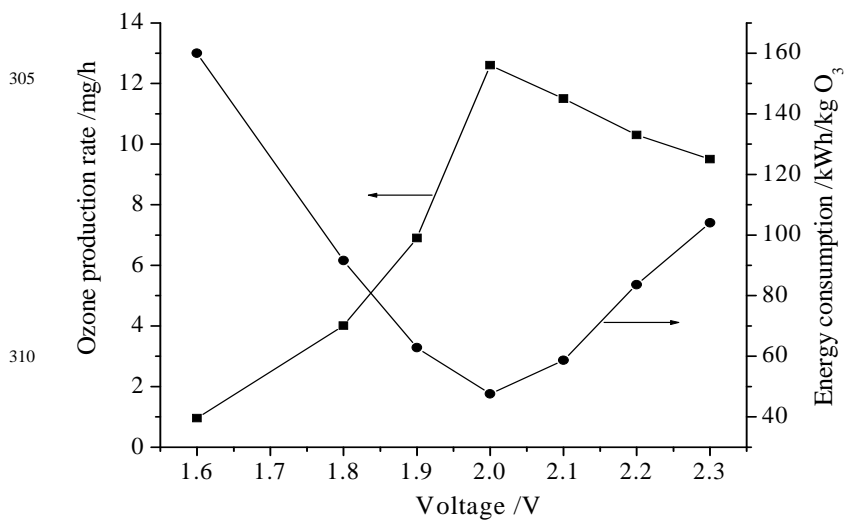

Figure 6. Applied voltage vs. ozone production rate and energy 315 consumption

\section{Energy efficiency}

The ozone production rate was the amount of ozone generated in a unit time period, and changes with the applied voltage, as shown in Fig. 6. The ozone was generated on a $4.0 \mathrm{~cm} \times 6.0$ $320 \mathrm{~cm}$ anode. In principle, the production rate scales with the electrode area, subject to limitations of uniform current distribution and mass transport. Experience of established electrochemical technologies, such as fuel cells and chloroalkaline production, are helpful to large scale 325 electrochemical generation of ozone. From Fig. 6, the highest steady-state ozone production rate was $12.6 \mathrm{mg} / \mathrm{h}$ achieved at a cell voltage of $2.0 \mathrm{~V}$ over a period of hours. The corresponding energy consumption per unit ozone was also shown in Fig. 6 . It varies with voltage in the trend opposite to 330 that of production rate. The energy consumption Ep in $\mathrm{kWhr} / \mathrm{kgO}_{3}$ is determined by:

$$
\mathrm{E}_{\mathrm{p}}=(\mathrm{V} . \mathrm{I}) / \mathrm{Q},
$$

335 where $\mathrm{Q}$ in $\mathrm{kg} / \mathrm{hr}$ is the ozone production rate, I in A is the current, and $\mathrm{V}$ in voltas is the applied cell voltage. From Fig. 6 , the lowest energy consumption of $48 \mathrm{kWhr} / \mathrm{kg}$ ozone was achieved at $2.0 \mathrm{~V}$. This energy consumption is lower than the lowest energy consumption reported $(65 \mathrm{kWh} / \mathrm{kg})$ on $\mathrm{PbO}_{2}$ 340 [27]. It was demonstrated on $\mathrm{PbO}_{2}$ electrode that forced convection can improve energy consumption by $50 \%$. We would expect a similar improvement when water is circulated through the anode compartment of the PEM cell. The best reported CD energy efficiency is $9.5 \mathrm{kWh} / \mathrm{kg}$ ozone, assuming 345 the supplies of cooling water, dry and pure oxygen are available [28]. Typical energy requirement is $2 \sim 3$ times this value when drying, cooling, and oxygen purification are all considered That should bring the energy efficiency of the electrochemical route compatible to the CD process.

350

The effect of current and voltage on efficiency as given in equation (4) gives some interesting insights to alternatives in the operation of electrolytic ozone generation. The electrochemical route requires a higher free energy barrier 355 since the starting raw material is water, compared to oxygen in the $\mathrm{CD}$ process. The possibility of electrooxidation of oxygen to ozone exists with the reaction

$$
\mathrm{O}_{2}+\mathrm{H}_{2} \mathrm{O} \longrightarrow 2 \mathrm{H}^{+}+2 \mathrm{e}^{-}+\mathrm{O}_{3}
$$

which is a 2 electron process with an equilibrium potential of $2.03 \mathrm{~V}$. If oxygen is produced electrochemically via equation (1), then the overall process is still a 6 e transfer and the energy consumption remains the same. If, however, oxygen 365 can be supplied to the anode, eg. via aeration, and with efficient mass-transfer, then there should be a substantial gain in energy efficiency. The cell voltage may increase with reaction (5), but the $1 / 3$ reduction in current per ozone produced can lead to an overall decrease in energy 370 consumption, as shown in equation (4). The concept of areated anode therefore warrants further investigation.

On the other hand, there also exists an alternative of hydrogen evolution to replace the oxygen reduction reaction at the 375 cathode, given as

$$
2 \mathrm{H}^{+}+2 \mathrm{e}^{-} \longrightarrow \mathrm{H}_{2}
$$

which has an equilibrium potential of $0 \mathrm{~V}$. The simultaneous 380 production of hydrogen may be desirable in some applications. In renewable energy applications, hydrogen is produced by electrolysis of water as stored or transportable energy. Oxygen is a byproduct of electrolysis that may not be discarded. Co-generating of ozone instead of oxygen in 385 electrolytic hydrogen production can be very desirable. The choice of hydrogen evolution in equation (6) over oxygen reduction in reverse of equation (1), however, will require a higher operating cell voltage due to the lower equilibrium potential. In addition, water will be consumed and needs to be 390 replenished steadily to keep the function of the PEM cell. But the generation of two useful products: hydrogen and ozone are of interest in environmental applications.

\section{Conclusions}

The advantages of the electrochemical route for ozone 395 generation are demonstrated with a polymer-electrolytemembrane (PEM) cell housed with a novel doped tin oxide anode. Compared to the conventional corona discharge process, the ozone concentrations in gas and dissolved phases are higher, there is no risks of nitrogen oxides byproducts, and 400 improved energy efficiencies are expected. The electrochemical route offers a modular, scalable production. Further improvements and optimization are expected by forced convection, more thoroughly contacted electrolyteanode interface, and alternatives in andoe and cathode 405 operations. The green synthesis of ozone should widen applications of ozonation for a better environment. 


\section{Aknowledgement}

410 This research has been supported by a Seed Funding from CRCG and a University Development Fund for Water Environment Engineering in the University of Hong Kong.

\section{References}

1 Korich DG, Mead JR, Madore MS, Sinclair NA, Sterling CA, Appl $415 \quad$ Environ Mirobiol 1990; 56, 1423.

2 N. P. Cheremisinoff, Handbook of water and wastewater treatment technology, Butterworth-Heinemann, 2002, pp449-465.

3 B. Langlais, D. A. Reckhow and D. R. Brink, Ozone in Water Treatment Application and Enginering, Lewis Publishers, 1991.

4204 E. Merz and F. Gaia, Ozone Science \& Engineering, 1990, 12, 401.

5 P. C. Foller and C. W. Tobias, J. Electrochem. Soc., 1982, 129, 506.

6 E. R. Kotz and S. Stucki, J. Electroanal. Chem., 1987, 228,407.

7 T. C. Wen and C. C. Chang, J. Electrochem. Soc., 1993, 140, 2764.

8 J. R. Feng, D. C. Johnson, S. N. Lowery and J. J. Carey, J. $425 \quad$ Electrochem. Soc., 1994, 141, 2708.

9 A. A. Chernik, V. B. Drozdovich and I. M. Zharskii, Russ. J. Electrochem., 1997, 33, 259.

10 N. Katsuki, E. Takahashi, M. Toyoda, T. Kurosu, M. Iida, S. Wakita, Y. Nishiki and T. Shimamune; J. Electrochem. Soc. 1998, 145, 2358.

43011 S. G. Park, G. S. Kim, J. E. Park, Y. Einaga and A. Fujishima, J. of New Materials for Electrochemical Systems, 2005, 8, 65.

12 L. M. Dasilva, M. H. P. Santana and J. F. C. Boodts, Quim. Nova, 2003, 26, 880.

13 S. D. Han, J. D. Kim, K. C. Singh and R. S. Chaudhary, Indian Journal of Chemistry, 2004, 43A, 1599.

14 S. A. Cheng and K. Y. Chan, Electrochem. Solid State Lett., 2004, 7, D4.

15 Y. H. Wang, K. Y. Chan, S. A. Cheng and X. Y. Li, J. Electrochem. Soc., 2005, 152, D197.

44016 Y. J. Feng and X. Y. Li, Water Res. 2003, 37, 2399.

17 M. A. Quiroz, S. Reyna, and J. L. Sanchez, J. Solid St. Electrochem. 2003, 7, 277.

18 Y. H. Wang, K. Y. Chan, X. Y. Li, and S. K. So, Chemosphere, in press.

44519 K. Rakness, G. Gordan, B. Langlais, W. Masschelein, N. Matsumoto, Y. Richard, C. M. Robson and I. Somiya, Ozone Science \& Engineering, 1996, 18, 209.

20 J. B. Fernando, Ozone reaction kinetcis for water and wastewater systems, Boca Raton: Lewis. 2004, pp78.

45021 A.K. Bin, Expt. Therm. Fluid Sci., 2004, 28, 295.

22 K. Koike, T. Fukuda, S. Ichimura and A. Kurokawa, Review of Scientific Instruments, 2000, 71, 4182.

23 E. Coleman, T. Siegrist, D. A. Mixon, P. L. Trevor and D. J. Trevor, Journal of Vaccum Science \& Technology A- Vaccum Surfaces and films, 1991, 9, 2408.

24 P. Tatapudi and J. M. Fenton, J. Electrochem. Soc., 1993, 140, 3527.

25 P. Tatapudi and J. M. Fenton, J. Electrochem. Soc., 1994, 141, 1174.

26 K. Onda, T. Ohba, H. Kusunoki, S. Takezawa, D. Sunakawa and T. Araki, J. Electrochem. Soc., 2005, 152, D177.

46027 S. Stucki, H. Baumann, H. J. Christen and R. Kotz, J. Appl. Electrochem., 1983, 17, 773.

28 S. Hanft, “Ozone Generation: Technologies, Markets and Players”, B.C.C. Business Opportunity Report, 2004, Norwalk, Connecticutt, pp. 150. 
